\title{
Quando a produção textual e o ensino de literatura ultrapassam as fronteiras escolares: uma experiência pedagógica no Colégio Técnico Industrial de Santa Maria
}

\begin{abstract}
Romário Volk ${ }^{1}$
Resumo

Esta narrativa tem o objetivo de expor as etapas e os resultados de um conjunto de atividades pedagógicas realizadas no Colégio Técnico Industrial de Santa Maria (Ctism), de abril a dezembro de 2017. Os eventos que são narrados desenvolveram-se a partir das práticas de Estágio Supervisionado em Língua Portuguesa e suas literaturas, disciplina obrigatória do Curso de Letras-Português da UFSM. Dois alunos estagiários, a partir de seus projetos de estágio, conduziram, juntamente com duas professoras da área de linguagens do Ctism, um projeto de produção textual de textos literários, o qual, vinculado aos projetos de estágio, possibilitou que os alunos dos 1으, 2으 e 3o anos do Curso Proeja - Técnico em Eletromecânica, produzissem, respectivamente, crônicas, um diário compartilhado, poemas e microcontos (estes últimos em língua espanhola) e, posteriormente, publicassem um livro que reúne as produções. O lançamento do livro ocorreu em um evento aberto à comunidade santa-mariense, o que contribuiu para que os alunos-autores percebessem o caráter humanizador dos textos literários e a escrita como forma de ação social, muito mais do que uma tarefa realizada com finalidades escolares.
\end{abstract}

Palavras-Chave: Produção textual. Literatura. Ação social.

\section{Resumen}

Esta narrativa tiene por objetivo presentar las etapas y los resultados de un conjunto de actividades pedagógicas realizadas en el Colegio Técnico Industrial de Santa María (Ctism), en el periodo de abril a diciembre de 2017. Los acontecimientos que se narran se desarrollaron a partir de la Práctica Tutelada en Lengua Portuguesa y sus Literaturas, una asignatura obligatoria del Curso de Letras-Portugués de la Universidad Federal de Santa María. Dos alumnos en periodo de prácticas condujeran - en conjunto con dos profesoras del área de lenguajes del Ctism y por medio de sus propuestas de enseñanza - un proyecto de producción de textos literarios. Este proyecto, vinculado a las propuestas de prácticas, posibilitó a los alumnos del 1ํ, 2ำ y 3o años del Curso Proeja - Técnico en Electromecánica producir, respectivamente, crónicas, un diario compartido, poemas y microcuentos (estos en lengua española). Después de esa producción, los alumnos han publicado un libro con el conjunto de esas producciones textuales. El lanzamiento del libro ocurrió en un evento abierto a la comunidad de la ciudad de Santa María, contribuyendo para que los alumnos/autores percibieran el carácter humanizador de los textos literarios y la escrita como forma de acción social, mucho más de lo que una tarea realizada con fines escolares.

Palabras-clave: Producción textual. Literatura. Acción social.

\section{Introdução}

O processo de ensino de linguagens é desafiador em qualquer contexto em que

\footnotetext{
1. Mestrando em Letras - Estudos Linguísticos, pelo Programa de Pós-Graduação em Letras da Universidade Federal de Santa Maria (UFSM). O presente trabalho foi realizado com apoio do CNPq, Conselho Nacional de Desenvolvimento Científico e Tecnológico - Brasil.
} 
ocorra, uma vez que o professor, em qualquer caso, estará mediando um processo que não pode desconsiderar o espaço sociocultural, a rede de valores e, por último, os anseios de alunos que advém, muitas vezes, de práticas sociais diversas e que acabam por constituir o espaço plural da sala de aula. Nesse sentido, cabe ao professor encontrar maneiras de fazer com que o seu objeto de estudo - no caso, a língua - contribua para uma formação humana do seu aluno, a fim de prepará-lo, muito mais do que apenas para uma formação técnica, para o mundo do trabalho.

Se, porém, isso já representa um desafio ao professor da escola básica, em que os alunos não possuem, de modo tão explícito, interesses por uma formação para o mundo do trabalho, o desafio torna-se ainda maior quando o contexto é um colégio técnico industrial, por exemplo, e, avançando ainda mais, uma turma do EJA, matriculada em um curso técnico em eletromecânica de um colégio técnico industrial. Esse foi o contexto em que se desenvolveram as atividades e práticas que passarei a expor e discutir no restante desta narrativa.

\section{O CONTEXTO DE DESENVOLVIMENTO DAS PRÁTICAS}

O Colégio Técnico Industrial de Santa Maria (Ctism) situa-se no campus da Universidade Federal de Santa Maria (UFSM). Vinculado a essa instituição, o Ctism atende, hoje, a aproximadamente 1500 alunos, muitos dos quais vinculados a cursos que possuem uma espécie de dupla formação (é o caso do ensino médio integrado a cursos técnicos, por exemplo, ou do Proeja, o ensino profissionalizante concomitante ao ensino médio na modalidade EJA).

Esse duplo direcionamento da formação dos alunos, os quais precisam ter contemplada a formação da escola básica e, também, das disciplinas técnicas que integram suas respectivas grades curriculares, preparando-os para o mundo do trabalho, pode - e na maioria das vezes interfere - no prestígio que o próprio aluno dá a uma e outra disciplina, elegendo esta ou aquela como "importante para a sua formação" a despeito de outra(s), consideradas, talvez, "dispensáveis". Portanto, o professor encontra-se em uma posição, 
muitas vezes, desfavorecida, em que sua disciplina concorre com outras. Para muitos profissionais isso pode ser visto como algo negativo, e o é, caso práticas adequadas não sejam tomadas, mas pode ser, por outro lado, o estímulo para que o professor encontre maneiras inovadoras de ensinar e envolver seus alunos. De forma mais resumida, a questão que aqui se coloca é: “Como posso agir para que um aluno que está em uma instituição técnica, buscando uma formação para o mundo do trabalho, perceba a importância, para a sua vida, de uma disciplina de língua portuguesa, de língua espanhola ou, mais ainda, de literatura"? Responder a essa pergunta motivou as práticas e ações que agora passo a narrar.

\section{ESTÁGIO SUPERVISIONADO EM LETRAS NA UFSM: O INÍCIO DE UM PROJETO PARA A VIDA}

Os cursos de Letras - licenciatura da UFSM determinam que os alunos graduandos, já a partir do quinto semestre regular, ingressem na sala de aula de escolas de ensino básico, a fim de realizarem observações contextuais e, posteriormente, dinamizarem seus projetos de estágio. A organização desse momento de formação dos alunos se dá da seguinte maneira:

1) No 5o semestre do curso: inserção em alguma turma de ensino fundamental: observação e construção do projeto de estágio;

2) No 6o semestre do curso: dinamização, na mesma turma, do projeto de estágio construído;

3) No 70 semestre do curso: inserção em alguma turma de ensino médio - observação e construção do projeto de estágio;

4) No 8o semestre do curso: dinamização, na mesma turma, do projeto de estágio construído.

As práticas às quais se refere esta narrativa correspondem às etapas 3 e 4 . Deram-se no âmbito do Ensino Médio, em uma turma do Curso Técnico em Eletromecânica, na modalidade Proeja.

\section{OS PASSOS ATÉ A IDEIA DO LIVRO COMPARTILHADO}


Inserimo-nos no contexto do Ctism em abril de 2017, a fim de realizar as atividades relativas ao período de observação da turma e da escola. Um de nós dois (ambos alunos do Estágio Supervisionado) em uma turma do 10 ano do Proeja e outro, em uma turma do 20 ano do Proeja. Depois, tornamo-nos parceiros no projeto que aqui narramos.

Já nas primeiras semanas da inserção no contexto da turma percebemos uma particularidade relevante: todos os alunos, na faixa etária entre 23 e 52 anos, trabalhavam durante o dia (as aulas eram noturnas) ou estavam em busca de emprego. Como motivá-los, então, em nossas futuras práticas do estágio, a lerem textos literários, produzirem textos e, em última instância, compreenderem que a disciplina de língua portuguesa e, em última instância, a aprendizagem sobre a língua são tão "importantes" para a formação dos alunos quanto as disciplinas práticas de laboratório e seus objetos de ensino, por exemplo? Afinal, os alunos estavam ali com dois objetivos claros: primeiro, concluir o ensino médio; segundo, juntamente a isso, obter uma formação técnica, para o mundo do trabalho.

Nossos projetos de estágio, transitando entre língua e literatura (a disciplina das turmas chama-se "Linguagens, códigos e suas tecnologias"), deveria abarcar essas duas grandes áreas e possibilitar que os alunos avançassem em ambos os campos do conhecimento, o que também exigiu que se equilibrassem as práticas, nunca desprestigiando nenhum conhecimento. Mas o que poderia, ingenuamente, ser visto como um entrave para a condução de práticas coerentes tornou-se a força motriz de um projeto de estágio pensado de maneira contextualizada: promoveríamos práticas que mostrassem aos alunos o caráter humanizador da literatura, buscando sensibilizá-los para o poder transformador e emancipatório da leitura e da escrita. Desenvolvemos, então, um projeto que objetivou mostrar aos alunos da turma do Proeja que o texto literário tem suas especificidades em relação a textos de outros campos de atividades humanas, como os gêneros jornalísticos, jurídicos, por exemplo. Mais do que isso, almejamos o desenvolvimento da consciência sobre a importância da leitura literária, ainda que isso pudesse ser visto, pela maioria, como uma "perda de tempo" para quem trabalha o dia todo e procura uma formação para o mercado de trabalho.

O Estágio Supervisionado em Letras prevê a possibilidade, no final do período de 
regência, da criação de um produto final, que deve compreender a produção de algum gênero textual, uma vez que todos os projetos de estágio devem possuir um gênero norteador. Em nossos projetos, particularmente, os gêneros escolhidos foram a crônica literária e o diário compartilhado, justamente por podermos, a partir desses gêneros, com seu caráter crítico-reflexivo, mostrar que um texto literário tem o poder de humanizar:

no exercício da literatura, podemos ser outros, podemos viver como os outros, podemos viver os limites do tempo e do espaço de nossa experiência e, ainda assim, sermos nós mesmos. É por isso que interiorizamos com mais intensidade as verdades dadas pela poesia e pela ficção (COSSON, 2016, p. 17)

Essa definição vai ao encontro do que definem também uma série de documentos oficiais de ensino, como as Orientações Curriculares Nacionais para o Ensino Médio, por exemplo, quando seu texto afirma que "a literatura possibilita a ampliação de horizontes, o questionamento do já dado, o encontro da sensibilidade, a reflexão, enfim, um tipo de questionamento diferente do científico, já que objetivamente não pode ser medido" (2006, p. 55).

Uma questão, no entanto, ainda se colocava: como fazer com que a escrita dos alunos gerasse um produto final que não se limitasse ao ambiente escolar, com fins escolarizantes, como tantas vezes ocorre, e os alunos percebessem que a escrita é para o mundo, para agir socialmente, e não para ser avaliada pelo professor, e o texto ser, depois, esquecido em uma gaveta? Começava, ali, a se desenhar um projeto maior, que engajaria os alunos e a comunidade escolar, integrando as disciplinas das áreas de linguagens e outros professores da área e da instituição.

Reunimo-nos com nossa professora regente (cada estagiário precisa ter uma professora, na instituição de ensino em que o estágio será desenvolvido, que seja a responsável por mediar o processo que transita entre a universidade e a escola de estágio). Surgiu, então, a ideia: reunir, no final do ano, os textos produzidos por nossos alunos (as crônicas literárias, o diário compartilhado, os microcontos - em língua espanhola - e os poemas.

\section{RETRATOS DO QUE VEJO: O PERCURSO DE ELABORAÇÃO}

LínguaTec, Instituto Federal de Educação, Ciência e Tecnologia do Rio Grande do Sul, Bento Gonçalves v. 3, n. 1, p. 131-142, jun. 2019. 
O passo inicial estava dado. Em agosto de 2017 teve início, em termos práticos, um projeto que culminaria, em 15 de dezembro do mesmo ano, no lançamento de um livro (Fotografia 1) em um evento aberto à comunidade. Agora, finalmente, os alunos poderiam passar a perceber com mais clareza que os seus textos, os quais já estavam em processo de escrita, seriam lidos por pessoas que não apenas o professor. As produções passariam pelas mãos de parentes, amigos, pessoas da comunidade em geral, enfim, de qualquer um que procurasse momentos de fruição literária. A escrita teria sentido, realizaria seu propósito social, porque, claro, não podemos deixar de reconhecer que a escola precisa avaliar seus alunos, mas esse não pode ser o fim maior dos textos que são produzidos pelos alunos. Saindo da escola, no fim da formação básica, alunos serão, para o restante da vida, atores sociais, interagirão com múltiplos gêneros textuais, em seu cotidiano, e não se pode admitir que a escola perca isso de vista.

\subsection{As crônicas literárias}

Correspondem a 23 textos que foram produzidos em três versões (escrita, reescrita e versão final), com base na proposta de correção textual-interativa proposta por Ruiz (2010). A autora afirma que essa perspectiva de avaliação textual faz com que o aluno perceba que há, para o seu texto, um interlocutor, muito mais do que um avaliador/corretor. Os interlocutores, no caso de todos os textos do livro produzido, passam a ser, então, o público em geral, dada a especificidade do texto literário.

O processo se deu de forma linear, de maneira que os alunos produziam, em aula, as versões dos textos e, sempre em torno de duas semanas depois, já com os textos avaliados pelo professor estagiário, uma nova versão era produzida. Entre a primeira versão e a versão final notou-se uma significativa mudança em relação aos aspectos textuais e, principalmente, ao empenho do aluno com a escrita do próprio texto. Para essa seção não foi construído um título geral, como foi feito nas outras seções da obra. Aqui, cada crônica recebeu um título estipulado pelo próprio aluno-autor. Exemplos de títulos são: "O trânsito e seus elogios", "A compreensão é o que faz a diferença", "De sempre, para a eternidade", "Encontro com sua 
guerreira", "Ponto de vista".

Para a escrita desse gênero textual, o ponto de partida foram perguntas norteadoras que o professor lançou durante as aulas, como as que seguem: "O que vale a pena ser observado na realidade que nos cerca?"; "Será que a nossa rotina não pode ser vista de uma maneira singular?". "O que o cotidiano pode nos ensinar a respeito da vida?"

Inicialmente os alunos encontraram algumas dificuldades para estabelecer relações entre sua vida cotidiana e uma possível temática para seu texto. Muitas vezes, só depois de escrita a primeira versão da crônica é que os alunos passaram a perceber que suas inquietações e seus pontos de interesses cotidianos poderiam ser ótimos "materiais" de construção para uma crônica e que, de fato, não há realidade sobre a qual a literatura não pode se pautar (e que a crônica literária é um gênero que realmente o faz de maneira extremamente significativa). O "despertar desse olhar singular" por parte do aluno se deu, muitas vezes, por meio das sugestões temáticas apontadas pelo professor nos momentos da avaliação da primeira e segunda versões dos textos produzidos.

A seguir apresentamos um fragmento de uma das crônicas produzidas:

\section{DE SEMPRE, PARA A ETERNIDADE}

Quanto tempo temos? Algumas horas ou minutos...

É isso que separa a minha presença da sua ausência. Seus batimentos diminuem, seus olhos vão se fechando aos poucos e em minha mente sinto o seu último latido ecoando por toda aquela sala onde estávamos. A saudade de chegar no quarteirão de casa e já lhe escutar latindo, pronto pra brincar...

Em alguns momentos meu coração aperta ao saber que não vou mais ter o confidente pra quem eu desabafava diariamente, e mesmo sabendo que não iria falar nada, você demonstrava me entender. A cada aperto no peito vem uma lembrança de quando quebrava algo e eu tinha que limpar, e por isso brigávamos muito [...] Sinto sua falta, meu amigo, e isso não tem fim.

(In: Retratos do que vejo, 2017, p. 15)

5.2 O diário compartilhado

Correspondem a 21 textos, produzidos pelos 21 alunos do 20 ano do Proeja. Sob supervisão principal do professor estagiário já mencionado anteriormente, essa etapa exigiu um empenho maior por parte dos quatro integrantes envolvidos com o projeto (as duas 
professoras do Ctism e os dois estagiários). Cada um dos alunos tornou-se responsável por narrar um dia da vida das personagens que seriam criadas pela própria narrativa, à medida que o texto fosse sendo escritos pelos alunos, e os textos, posteriormente reunidos em um todo coerente, dariam origem ao diário compartilhado "Surpresas de uma vida fragmentada", que compõe a segunda parte do livro produzido. Para dar linearidade ao processo, um caderno foi entregue ao primeiro aluno-autor, que deu início à narrativa. Depois de um dia em posse do caderno e narrado um dia da vida da personagem, o aluno deveria entregar o caderno a um colega, o qual deveria, a partir do que já estava narrado, seguir com a escrita, compondo outro dia da personagem, e assim sucessivamente, até que cada um dos 21 alunos tivesse produzido seu texto.

A dificuldade maior, nessa etapa, foi o fato de que, muito rapidamente, às vezes depois de apenas dois dias narrados, a personagem principal "morria", o que prejudicava o andamento da narrativa, principalmente, porque os alunos que seguiriam com a escrita encontravam dificuldades com a "criatividade" necessária à produção do texto. Assim, os professores envolvidos adotaram uma medida: criar um roteiro, uma espécie de "espinha dorsal" para a narrativa, processo que era atualizado de acordo com os encaminhamentos que cada aluno ia dando à produção. Reconhecemos que talvez essa tenha sido uma medida "pouco democrática", mas tomamos o cuidado, ao máximo, para, mesmo interferindo no texto, deixar abertas várias possibilidades e caminhos para a narrativa. A seguir, apresentamos um fragmento da narrativa:

O7 DE JANEIRO, SEGUNDA-FEIRA

Acordei às 5h50, fiz a mesma rotina de todos os dias. Estava feliz pela conversa que tive com minha esposa na noite passada, me senti forte para seguir em frente.

Chegando ao trabalho, ainda não estava me sentindo realizado no desenvolvimento de minhas funções, por isso me perguntava, insistentemente, o que eu poderia fazer para melhorar [...]

A partir de então, comecei a procurar uma escola para fazer um curso preparatório para o ENEM, porque desejo voltar a estudar para poder oferecer uma melhor condição de vida para a minha família. Quando cheguei em casa, me envolvi na pesquisa de um bom cursinho.

(In: Retratos do que vejo, 2017, p.46)

\subsection{Os microcontos}


Correspondem a 9 textos em língua espanhola produzidos pelos alunos do $2^{\circ}$ ano do Técnico em Eletromecânica (Proeja). O número de textos é bem menor que o de alunos porque foram organizados grupos de dois a três alunos para a produção de cada texto. A produção, que recebeu como título "Microcuentos" teve como mediadora a professora de língua espanhola. Por meio de um procedimento metodológico semelhante àquele adotado para a produção das crônicas, com escrita da versão inicial e duas reescritas, os alunos foram instigados a escrever, em grupos de dois a três integrantes, microcontos que representassem uma maneira de reflexão sobre o cotidiano. A seguir, apresentamos um dos microcontos produzidos:

\section{ACCIDENTADO}

Dirigiéndome a casa pienso en mi futuro. Sucede el imprevisto en mi recurrido. El destino cambia instantaneamente.

(In: Retratos do que vejo, 2017, p. 75)

\subsection{Os poemas}

Correspondem a 8 textos produzidos pelos alunos do 3ㅇ ano do curso de Eletromecânica - Proeja. O processo ocorreu por meio de mediação conjunta, dos quatro professores envolvidos. Da mesma maneira que ocorreu com as produções anteriores, foi sugerido que os poemas fossem escritos a partir da reflexão dos alunos sobre aspectos da realidade que eles vivenciam, das observações do cotidiano. A temática foi, portanto, de livre escolha, contanto que atendesse a esse ponto específico.

Da mesma maneira que os gêneros já mencionados, os procedimentos de produção compreenderam a escrita de uma primeira versão e sua reescrita em mais duas versões, e com os professores realizando correções textuais-interativas, dando sugestões de adequações composicionais e temáticas.

Apresentamos um dos poemas produzidos:

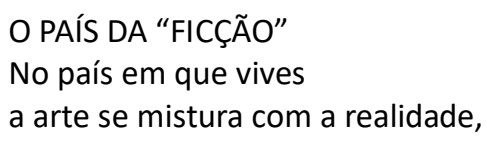


lá no morro a encenação do Projac se repete sem dublês, são pessoas que descem e sobem o morro e outras que nunca descerão.

$[\ldots]$

(In: Retratos do que vejo, 2017, p. 85)

\section{O LANÇAMENTO DO LIVRO “RETRATOS DO QUE VEJO”}

Com os textos produzidos, foi hora de organizar a produção em um livro e, por isso, optar por um nome que representasse o processo e o que os alunos-autores tinham a dizer. Surgiu, assim, "Retratos do que vejo", uma vez que a temática que perpassa os textos produzidos é o jeito singular que se pode olhar para a vida, para o cotidiano, a fim de tornálo mais leve e significativo.

Contando com o apoio da equipe de Editoração do Colégio Técnico Industrial de Santa Maria e com recursos financeiros oriundos de diversos centros de ensino da Universidade Federal de Santa Maria, foi possível imprimir em torno de 300 exemplares do livro, além de organizar um evento de lançamento do livro, ocorrido no dia 15 de dezembro de 2017, em um auditório da UFSM. O evento contou com diversas atrações, números musicais, performance de artistas e, mais importante, a presença dos familiares e amigos dos alunosautores.

Fotografia 1. O livro "Retratos do que vejo"

Fonte: $\mathrm{O}$ autor 


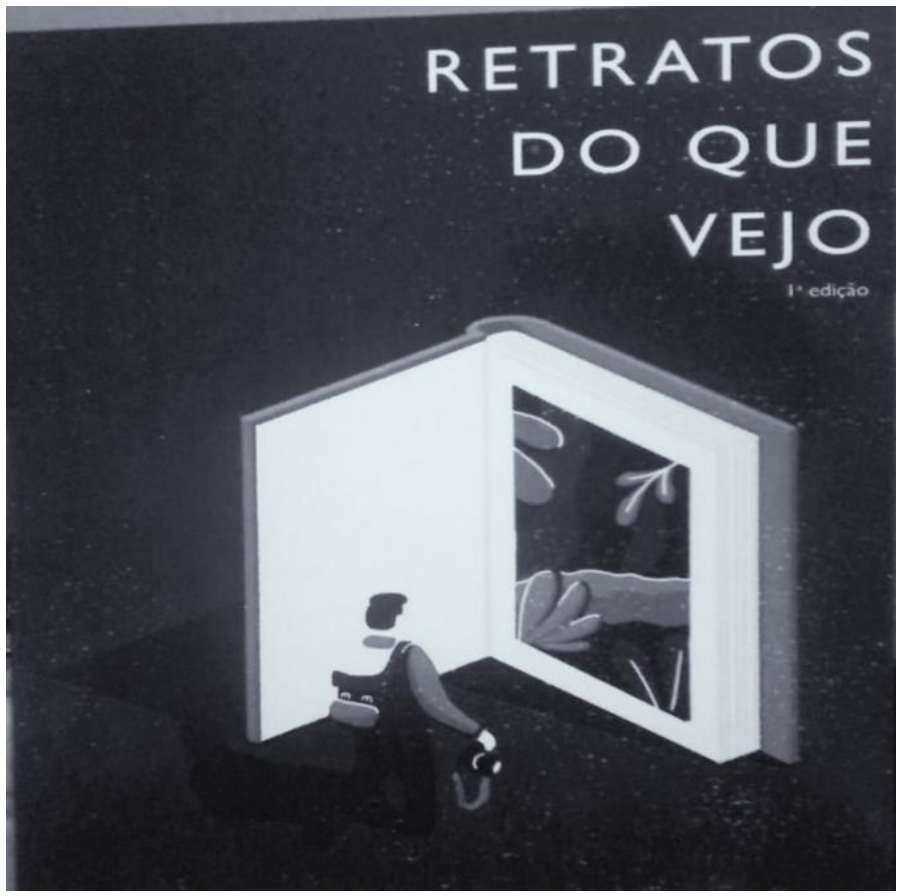

\section{7 “A BELA LIÇÃO DO PROEJA”: CONSIDERAÇÕES FINAIS}

As aspas do título acima reproduzem o título dado ao texto de apresentação do livro. De fato, o processo que se concluiu com o lançamento do livro mostrou que a escrita só alcança seu verdadeiro potencial se mediar as interações humanas, se estiver em funcionamento em seu "hábitat natural". O que na maioria das vezes ocorre, no processo de produção textual, é a escolarização da escrita, processo que reduz essa atividade ao âmbito escolar, e que faz com que os alunos compreendam escrita e textos como sendo algo destinado unicamente à avaliação do professor. Isso gera falta de motivação para a produção textual e, em longo prazo, cidadãos que, por lacunas deixadas pela escola, são incapazes de produzir, ler e interagir com os textos que fazem parte da sua prática cotidiana. A literatura, por sua vez, passa a ser vista de forma desconexada realidade, algo que só aumenta a já existente lacuna entre, por exemplo, cânone e literatura popular, ou então o texto literário e, por conseguinte, a literatura em si, é concebida, na visão dos alunos, como algo desnecessário, irrelevante, que nada tem a dizer. Também nesse sentido, o projeto contribuiu para que os alunos percebessem que a literatura muda a vida das pessoas, torna-as mais 
atentas ao cotidiano, desenvolve senso crítico e, mais do que isso, que cada um de nós pode escrever textos literários.

Em um contexto educacional que apresenta, muitas vezes, disciplinas que "concorrem" entre si, disputando importância ao invés de serem vistas como complementares - e isso em relação a alunos e professores - essa experiência mostrou que é possível repensar iniciativas e práticas em qualquer contexto, e que a literatura e a linguagem encontram solo fértil em qualquer espaço social, desde que professores e demais envolvidos nos processos educacionais não possuam visões enviesadas sobre concepções que estão inerentes ao seu objeto de estudo.

\section{Referências}

BRASIL. Secretaria de Educação Básica. Orientações curriculares para o ensino médio: linguagens, códigos e suas tecnologias. Brasília: Ministério da Educação, 2006.

COSSON, R. Letramento literário: teoria e prática. 2 ed. 6 re. São Paulo: Contexto, 2016.

HOLZSCHUCH, G.J.; BAZZAN, M. A. T. (Orgs.). Retratos do que vejo. 1 ed. Santa Maria: UFSM, 2017.

RUIZ, E. D. Como corrigir redação na escola: uma proposta textual-interativa. 1 ed. 1 re. São Paulo: Contexto, 2010.

Data de submissão: 05/04/2019. Data de aprovação: 19/05/2019. 